\title{
COMPARATIVE STUDY FOR BUCKLING RESISTANCE OF STEEL SHEETS PROVIDED WITH STIFFENERS USED IN BRIDGE STRUCTURES
}

\begin{abstract}
MARIAN DARABAN - Assistant, PhD, Technical University of Civil Engineering, Faculty of Railways, Roads
\end{abstract} and Bridges, e-mail: marian_daraban@cfdp.utcb.ro

\begin{abstract}
The subject discussed in this paper is based on an experimental bridge model which was built to study the pre-critical and post-critical buckling behaviour of steel webs of box girders provided with longitudinal and transversal stiffeners. The article presents a comparison between the experimental results and the numerical ones for buckling resistance of stiffened steel webs. For this purpose two types of analysis will be carried out: an analysis to establish the values and eigenvectors of buckling, after which the critical factor for the first mode of buckling will be obtained, and then a geometrical and physical nonlinear analysis will be performed.
\end{abstract}

Keywords: steel bridges, critical buckling analysis, nonlinear analysis.

\section{Introduction}

The main feature of modern bridge structures with I girders or box girders is the use for webs, and for flanges respectively in the case of box girders, of thin webs provided with stiffeners in one or two orthogonal directions. In determining the thickness of the webs, the number and the position of the stiffeners, the stability problems have the decisive role.

The first researches in the area were made since 1850 by a team consisting of an engineer of bridges and railways, R. Stephenson, a shipbuilder and a mathematician, and E. Fairbairn W. Hodgkinson, who designed and built the famous bridges Conway and Britannia in Great Britain. The bridges have maximum spans of $122 \mathrm{~m}$, and $142 \mathrm{~m}$, respectively, being the first steel bridges with large openings, which were made by using steel box girders made of stiffened thin webs and flanges.

Between 1907 and 1936 Timoshenko [3] developed what it is called the theory of linear buckling. In his studies, he approached the problem of buckling stability of webs provided with stiffeners. He also introduced the concept of relative rigidity for stiffeners, a notion underlying the establishment of stiffener dimensions.

The calculation method that is based on the linear buckling theory was developed almost to perfection by prof. K. Klöppel and his collaborators. They published two works of reference [4], [5] between 1960 and 1968.

The linear buckling theory is based on very restrictive assumptions which are never carried out in real structures. The structural elements which are madeindustrially, have numerous imperfections: the initial deformation, the deformations due to the thermal welding process, the initial residual efforts or the ones that are due to welding, various eccentricities appearing in the case of joints, etc. All these imperfections were reduced in the old structures of riveted bridges.

Between November 1969 and November 1971 serious accidents occurred during the construction of four steel bridges with box girders that had large openings: the bridge over the Danube in Vienna, November 6, 1969, the bridge Milford Haven in the UK, June 2, 1970, the bridge over the Yarra in Melbourne, Australia, October 15, 1970 and the bridge over the Rhine at Koblenz November 10, 1971. These accidents highlighted the shortcomings of the linear buckling theory which was the basis of design specifications in most countries. 
Therefore, it is necessary, for the stability problems of modern structures of bridges with I girders and box girders, that corrections to the results obtained with the theory of linear buckling be applied, with a view to cover the adverse effects of imperfections that inevitably occur in practice. Corrections should be based on the good knowledge of post critical behavior of each element of the structure and of the whole structure.

If the frames subjected to compression have no post critical resistance reserves beyond the buckling load, the thin girder webs resting on the 4 sides and subjected to compression in their plan, the post critical strength reserve might be important because of the possibility of redistribution of stresses after buckling, when the webs take a new configuration of stable equilibrium.

One of the possible methods for analyzing the post critical behavior of structures with thin webs is the one based on the nonlinear theory. This method raises problems because of the simultaneous influence of geometric nonlinearity, material nonlinearity, interaction between webs and flanges and because of the influence of numerous longitudinal stiffeners.

\section{Description of physical model}

The tested girder was made of OL37-4K steel and the shape and dimensions can be seenin figure 1 . The test results are analyzed in paper [1].

The web of the girder is divided into seven panels, of which 6 , those between the bearing sections and the sections of the application of external concentrated forces, are provided with longitudinal stiffeners. The web thickness is of $4 \mathrm{~mm}$, thereby a slenderness that falls in the large slenderness domain is achieved. The central panel web thickness is of $10 \mathrm{~mm}$.

Web panels have the sides ratio $\alpha=0,75, \alpha=1,00, \alpha=1,25$. These ratios are frequently met in the design of steel bridges. In terms of side panel reports, the model has four identical panels with the same longitudinal stiffener sections and the same distribution of stiffeners on the vertical direction. In all web panels, the longitudinal stiffeners and the transverse ones (except the sections for the application of concentrated forces P) were provided as non-symmetrical, on the inner wall box, a solution commonly used in modern steel bridge structures. The intermediate transverse stiffeners were provided with the same section. This section was obtained by respecting both the condition of rigidity which ensures the formation of a nodal line and the condition of resistance for taking over the vertical component from the tensile force of the diagonal field of the web panels.

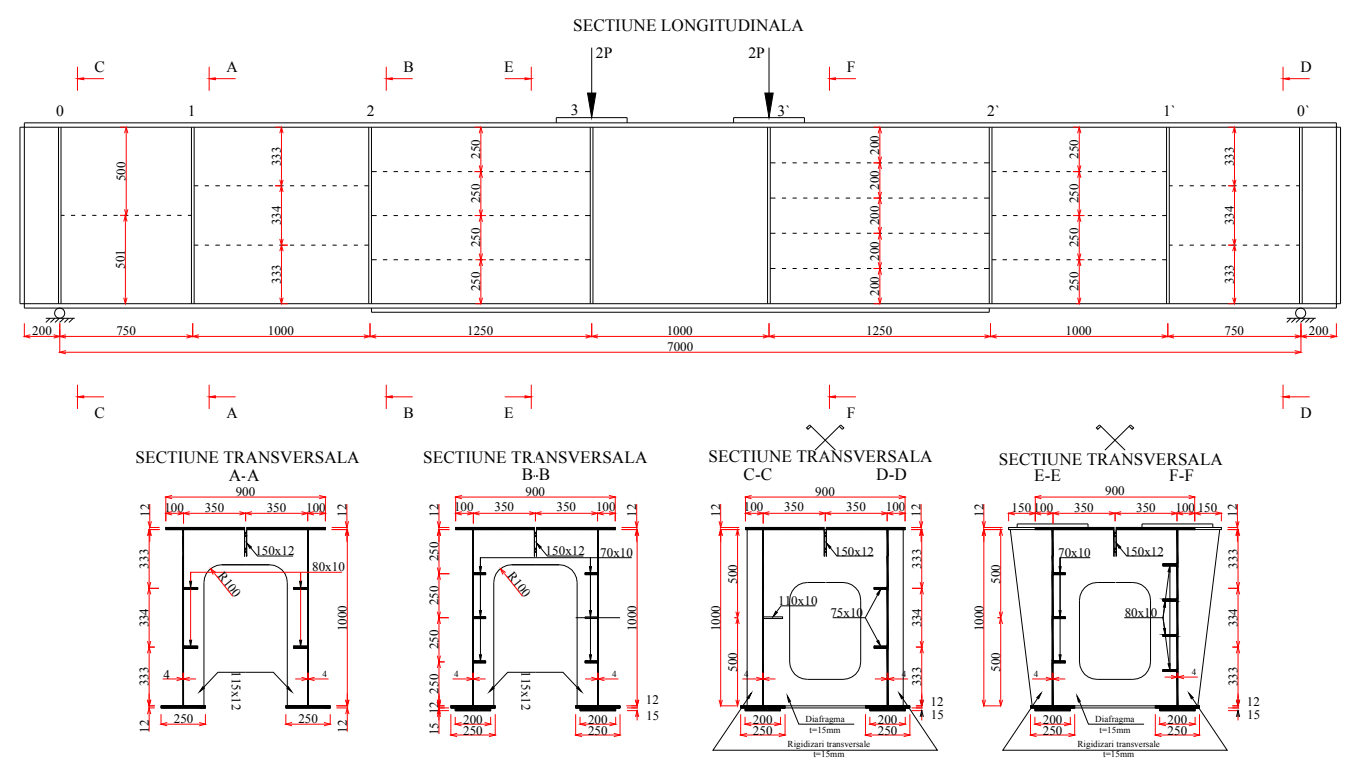

Fig. 1 - The physical model geometry 


\section{Description of finite element model}

For structural modeling the automatic calculation program Lusas has been used.Were used finite elements THICK SHELL, in this case finite element QTS8, 14.267 elements and finite element TTS6 340 items, with each node by 6 degrees of freedom (three translations and three rotations) defined in local coordinate system of each finite element joint.

QTS8

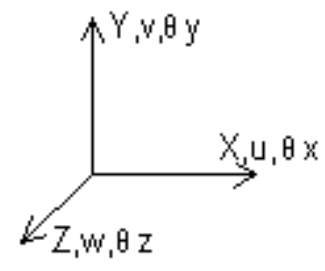

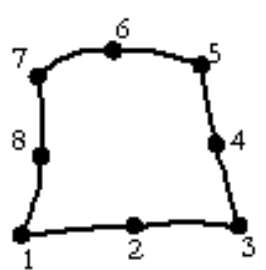

TTS6

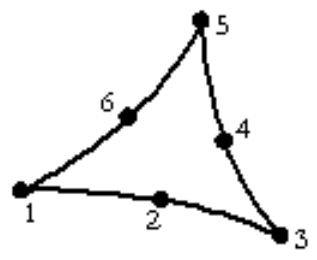

Fig. 2 - Lusas finite elements which have been used for structural FEA modeling
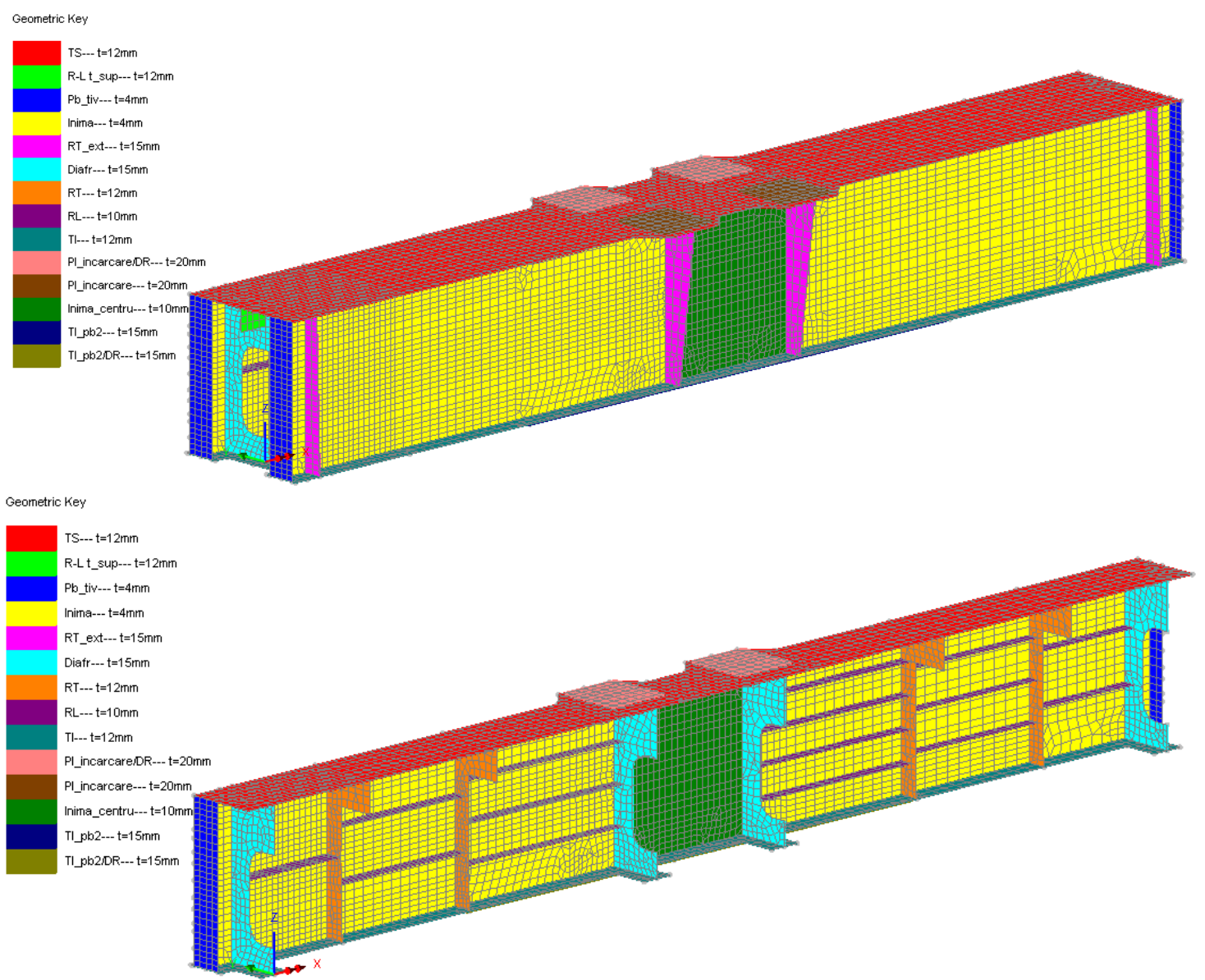

Fig. 3 - Lusas finite element model discretisation

Finite element QTS8 with 4 sides and 8 joints, takes an initially specific strain for transverse shear strain interpolation. This assignment of a specific strains shall be adopted in the case of thin plate elements that neglects transverse shear deformation. Displacements and rotations are considered independent and the nodal degrees of freedom are: $U, V, W, \theta_{\alpha}, \theta_{\beta}$ for each node.

\section{Results of the analysis}

Two types of analyses were made: first, an analysis to establish the values and eigenvectors for buckling, as a result of which the critical buckling factor value was obtained for the first mode of 
buckling and then a geometric and physical nonlinear analysis. For this type of analysis - the values and eigenvalues - the material is considered infinitely elastic, in this case having elastic modulus $E=21 \cdot 10^{6} \mathrm{tf} / \mathrm{m}^{2}$, the Poisson's ratio $v=0.3$ and the volume weight $\gamma=7,85 \mathrm{tf} / \mathrm{m}^{3}$.

The properties of the material are specified in the orthogonal system of axes. For the isotropic material the matrix D has the expression:

$$
D=\frac{E}{1-v^{2}}\left[\begin{array}{ccccc}
1 & v & 0 & 0 & 0 \\
& 1 & 0 & 0 & 0 \\
& & \frac{1-v}{2} & 0 & 0 \\
& & & \frac{1-v}{2.4} & \\
& & & & \frac{1-v}{2.4}
\end{array}\right]
$$

In the middle, the box girder is provided with four steel plates with the area $A=0,16 \mathrm{~m}^{2}$. Each of the plates is loaded by a hydraulic press with the load $P=0,8 t f$, obtaining a pressure on each, of $p=5 \mathrm{tf} / \mathrm{m}^{2}$. Nonlinear geometric analysis provided the load factor $\lambda=58,8965$. The results is the critical load $P_{c r}=0,8 \cdot 58,896=47,117 t f$

Deformed shape for the first buckling mode:

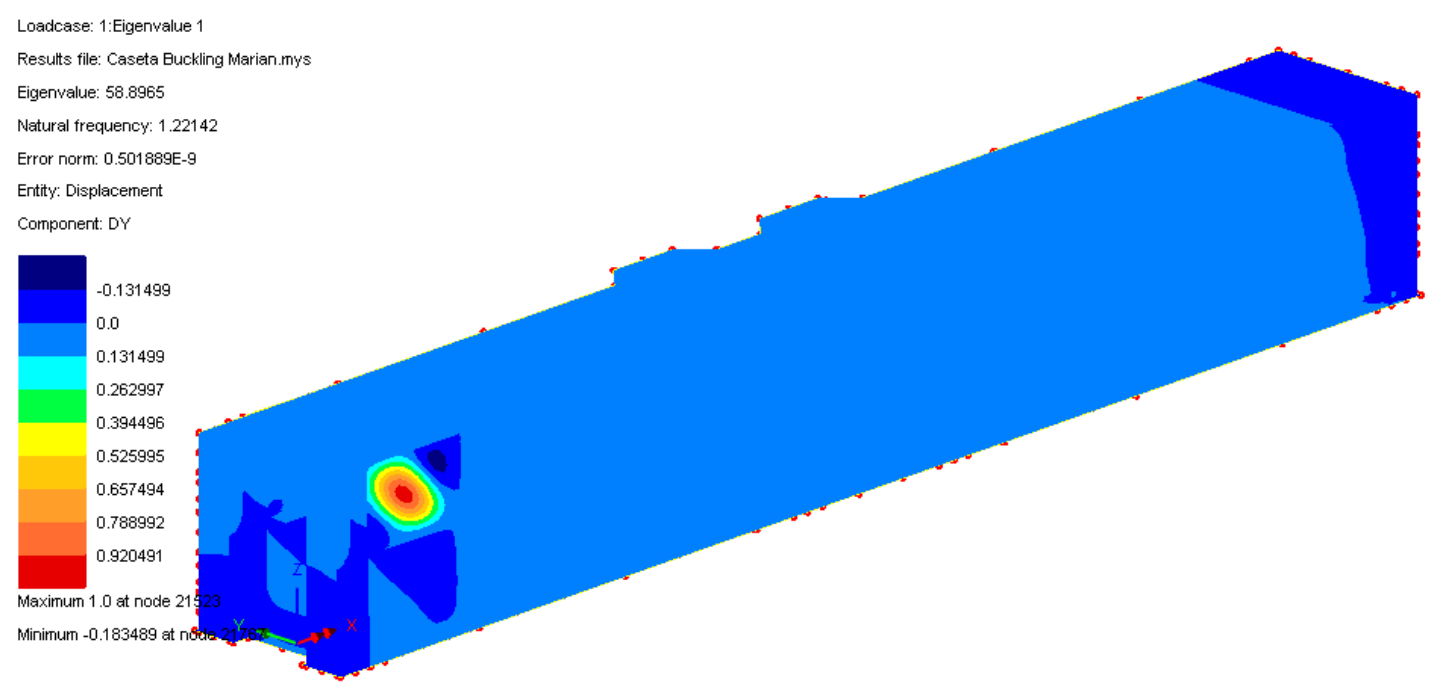

Fig. 4 - Deformed shape for first buckling mode

The calculated value of $P_{c r}=0,8 \cdot 58,896=47,117 \mathrm{tf}$ does not include the weight of the box, whose value is $G=2,4 t f$.

The analysis of values and buckling eigenvalues is important as it provides an approximate value of the critical buckling load that will be used in a nonlinear analysis.

\section{Geometrically nonlinear analysis of the structure [2]}

The principle of the used method (Method arc length) is based on the following equation for determining the loading increments:

$$
\{\delta u\}_{i}^{1 T}\{\delta u\}_{i}^{j}+\lambda_{i}^{1} \lambda_{i}^{j}=(\delta S)^{2}
$$


where $\{\delta u\}_{i}^{1}$ şi $\{\delta u\}_{i}^{j}$ represents the incremental displacements for the first iteration and for iteration $j$ of the incremental step $i$ and $\delta S$ is the arc length of the corresponding tangent to the load displacement curve $(P-u)$ of the previous step $i-1$, wherein the solution has converged.

$$
\begin{aligned}
& \delta S=\left\{\begin{array}{l}
\text { const }, j=1 \\
0, j \geq 2
\end{array}\right. \\
& \{\delta u\}_{i}^{j}=\lambda_{i}^{j}\{\delta \hat{u}\}_{i}^{j}+\left\{\delta u^{R}\right\}_{i}^{j}
\end{aligned}
$$

For each incremental step in the first iteration, $\mathrm{j}=1$, there are no unbalanced forces, so $\left\{\delta u^{R}\right\}_{i}^{1}=0$ . It follows therefore, taking into account the relation (4):

$$
\begin{aligned}
\{\delta u\}_{i}^{1} & =\lambda_{i}^{1}\{\delta \hat{u}\}_{i}^{1} \\
\lambda_{i}^{1} & = \pm \frac{\delta S}{\sqrt{\left\{\{\delta \hat{u}\}_{i}^{1}\right\}^{T}\{\delta \hat{u}\}_{i}^{1}+1}} \quad \text { for } \mathrm{j}=1
\end{aligned}
$$

This relation is exactly the load factor to be applied at the beginning of the incremental step $i$. The "+" sign in the expression (6) relates to the stage of loading the structure and the "-" at the stage of unloading. For $j \geq 2$ iterations are made so that there is no change of arc length $\delta S$.

Considering again the relation (4) and inserting it in (2) and taking into account that $\delta S=0$ for $j \geq 2$, the loading parameter $\lambda_{i}^{j}$ result:

$$
\lambda_{i}^{j}=-\frac{\left\{\{\delta u\}_{i}^{1}\right\}^{T}\left\{\delta u^{R}\right\}_{i}^{j}}{\left\{\{\delta u\}_{i}^{1}\right\}^{T}\{\delta \hat{u}\}_{i}^{j}+\lambda_{i}^{1}}, j \geq 2
$$

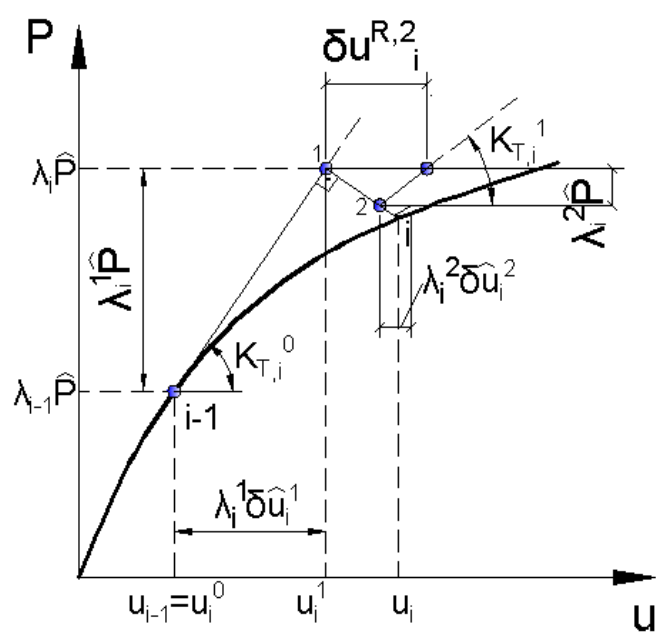

Fig. 5 - The arc-length method [2]

\section{The results of nonlinear analysis}

\subsection{0-1 panel}

The deformed shape of the 0-1 panel with the isocurved of $Y$ axis displacements for the load factor 61,5236 which corresponds to a loads on each press equal with $P=61.5236 \cdot 5 \cdot 0.16=49,21 t f$. 


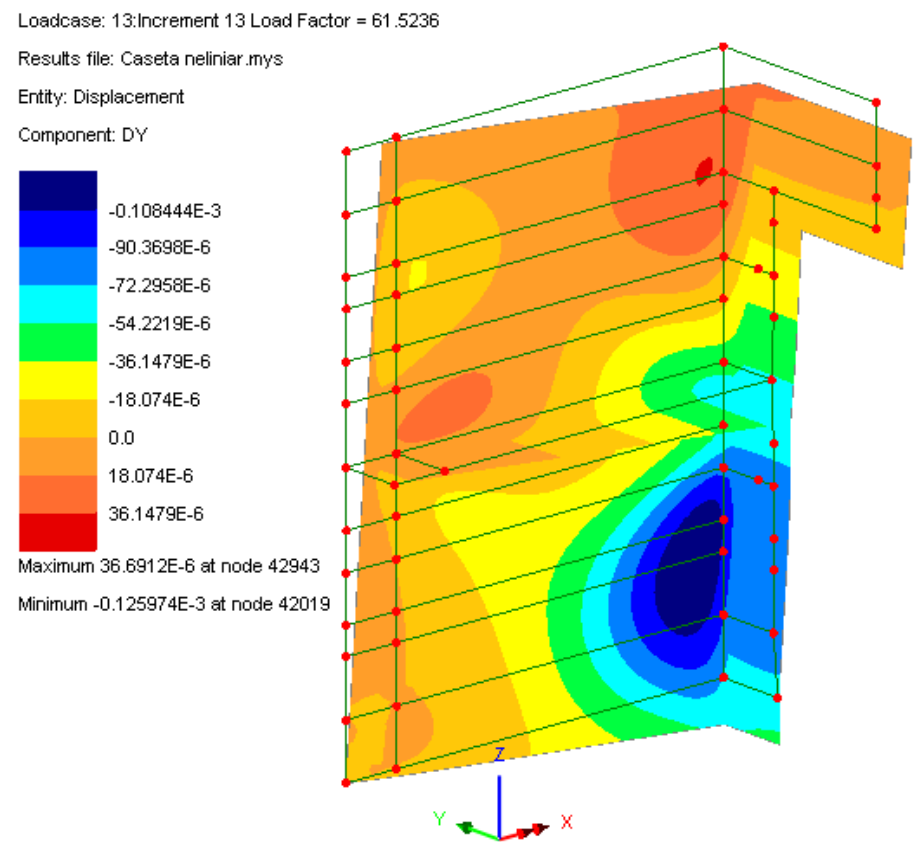

Fig. 6 - The deformed shape of the 0-1 panel with the isocurved of $\mathrm{Y}$ axis displacements

The experimental value of the ultimate strength of the web panel which was experimentally determined is $50 \mathrm{tf}$.

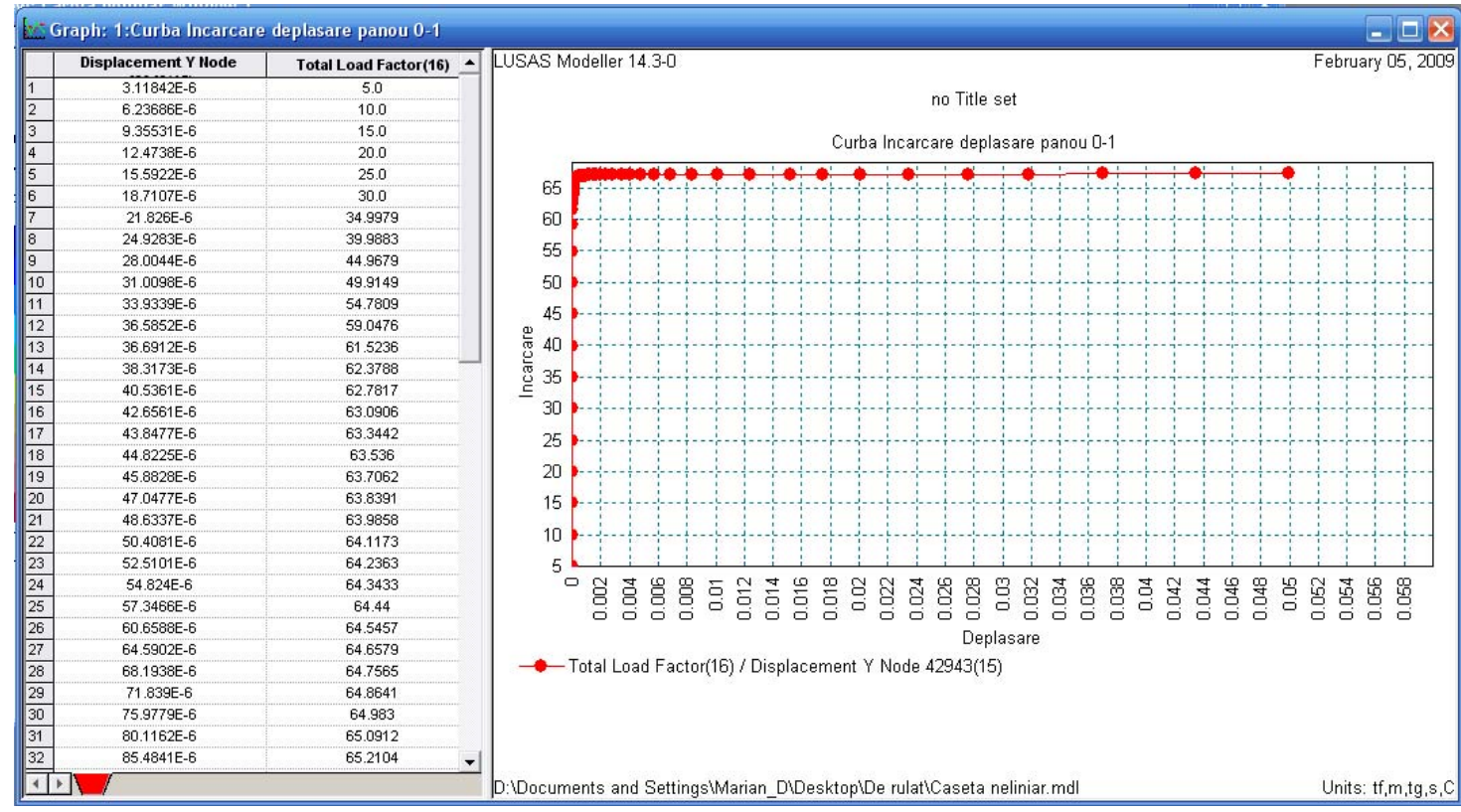

Fig. 7 - The P- $\Delta$ curve for 0-1 panel

\subsection{1-2 panel}

The deformed shape of the 1-2 panel with the isocurved of $\mathrm{Y}$ axis displacements for the load factor 65,0912 which corresponds to a loads on each press equal with $P=65,10912 \cdot 5 \cdot 0.16=52.07 \mathrm{tf}$.

The experimental value of the ultimate strength of the web panel which was experimentally determined is $55 \mathrm{tf}$. 


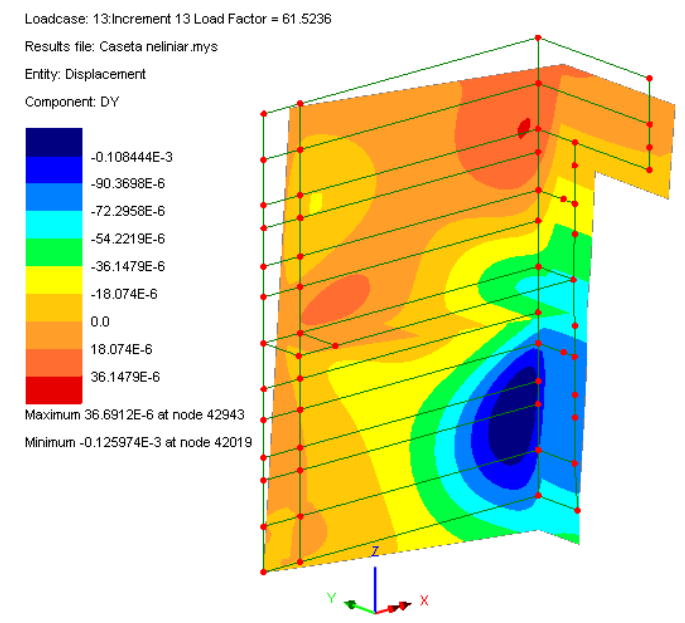

Fig. 8 - The deformed shape of the 1-2 panel with the isocurved of $Y$ axis displacements



Fig. 9 - The P- $\Delta$ curve for $0-1$ panel

\section{Conslusions}

For the nonlinear analysis the Total Lagrange formulation was used as well as the arc length method reformulated by Crisfield. Moreover, the nonlinear behavior of the material was considered, which has yield strength $\sigma_{c}=230 \mathrm{~N} / \mathrm{mm}^{2}$. The analysis contains a total of 75 load increments, each increment containing 4 iterations. The first increment value is $0,8 \mathrm{tf}$. For calculation convergence, the amount of load factor was adopted as variable. The total value of the load to which the analysis was performed is $60 \mathrm{tf}$ for each hydraulic press. Arc length method does not require iterations with constant load or constant displacement value and offer better opportunities to overflow the limit points.

\section{References}

[1] Popa N. (1986) Contribuţii la calculul şi alcătuirea podurilor metalice cu grinzi cu inimă plină şi casetate. Teză de doctorat. UTCB;

[2] Răcănel I. R. (2007). Stabilitatea podurilor metalice cu imperfecţiuni de execuţie. Ed. Conspress UTCB;

[3] Timoshenko S.P. (1936) Theory of elastic stability, Mc Grow-Hill, New York;

[4] Klöppel, K Möller, K.H. (1960). Beulwerte ausgesteifter Rachteckplatten. Wilh. Ernst, Berlin;

[5] Klöppel, K Möller, K.H. (1968). Beulwerte ausgesteifter Rachteckplatten, Wilh. Ernst, Berlin;

[6] P. Dubas and E Gehri (1986). Behaviour and Design of Steel Plated Structures. 